\title{
Procedural Knowledge of Graphic Design for Analysing Graphic Elements in Historical Urban Maps
}

\author{
Chenyang Xie
}

University of Portsmouth, yangworkemail@gmail.com

\begin{abstract}
Early modern maps are important records of urban development, providing detailed information on changing social and economic patterns, as well as offering insights into historic techniques of cartographic representation. On maps, a variety of information is translated to readers through graphic elements. The functions and meanings of graphic elements such as symbols and colour are known from and widely applied in graphic design. This paper discusses links between graphic design and historical urban maps, to explore a new interdisciplinary perspective to develop further the understanding of functions and meanings of graphic elements within historical urban maps. In particular, graphic design methods are here used to analyse historical hand-coloured London maps produced before the $19^{\text {th }}$ century. There are few records detailing the visual properties of historical London maps. In this context, it may be useful to apply graphic design research methods such as visual analysis and semiotics. Focussing on examples from maps in the $15^{\text {th }}$ and $16^{\text {th }}$ centuries, we suggest that graphic elements such as shape and colour could have been utilized by artists for specific functions and purposes, arguably making these maps early forms of graphic design. Furthermore, information design principles may be used to further the analysis of historical urban maps, in particular the way colour is used for coding information. These findings suggest graphic elements have historically been used to translate information on urban maps, which can create much richer meanings on maps than previously understood.
\end{abstract}

Keywords: historical urban map; graphic design; graphic element; visual language; colour

\section{Introduction: Understanding Historical Urban Maps through Graphic Design}

'Throughout history, humans have systematically designed and delivered information in an effort to share their perceptions of the world and persuade others to reach the same conclusions' (Jacobson, 1999, p.1).

Although there is some disagreement about the exact date of origins of graphic design (Crowley \& Jobling, 1996; Triggs 2011), graphic design is referred to as a discipline in either the late nineteenth (Eskilson, 2012) or in the early twentieth century (Crowley \& Jobling, 1996; Lupton \& Phillips, 2008). For example, graphic design is found in the twentieth century in American advertisements, which is understood as art with a commercial purpose (Crowley \& Jobling, 1996). Thus how graphic design can be applied to historical urban maps, especially those that were published before the nineteenth century, needs to be considered.

\section{Graphic Design and Maps as a Form of Visual Communication}

Graphic design has been argued to be a form of visual communication (Barnard, 2013; Chen \& Yu, 2016; Noble, 2016; Opach, 2009; Salchow, 1997). It is the use of sign systems to represent cultural meanings through different media (Barnard, 2013; Chen \& Yu, 2016; Cosgrove, 2005; Crowley \& Jobling, 1996; Jervis, 1936; Walker, 2017). These visual signs translate information, for communication, in a graphic manner (Chen \& Yu, 2016). Urban maps seem to be similar.

Similarities between graphic design and cartography have been found (Opach, 2009). Maps, in essence, are a resource for visual communication (Hodgkiss, 1981; Opach, 2009; Propen, 2007), and the graphic elements on maps represent detailed information for communication (Andrews, 1996; Propen 2007). For example, maps have been said to be an artificial representation of the world that presents information for readers (Owen, 2005; Propen 2007). Historical urban maps are often considered to be merely illustrations containing colours (Bagrow, 1964; Bagrow, 2010; Lynam, 1953; Skelton, 1966; Thrower, 1972; Whitfield, 2006). For example, historical urban maps are 'pretty views' of cities via an idealised aesthetic, social technique and architectural understanding to guide readers (Bagrow, 1964; Bagrow, 2010; Brotton, 2014; Ehrensvärd, 1987; Lynam, 1953). Thus, both maps and graphic design works are artistic creations using visual media for communication (Opach, 2009). Therefore, for the purposes of this investigation, urban maps can be viewed as a form of graphic design.

This means there is the possibility that graphic design principles were applied by the creators of early urban maps much earlier than the term 'graphic design' was. A graphic design perspective, which has previously been used for archival research culture in historical images (Walker, 2017), can thus be extended to include urban maps. This 
not only brings a new perspective to understanding maps, but also a fresh area for graphic design research.

\subsection{Common Aims: Informative, Decorative and Representative Functions}

Another way of understanding the link between graphic design and cartography is through an analysis of their aims. Graphic design includes informative, decorative, social, political, royal, cultural and economic functions, intentions and purposes (Barnard, 2013; Feldman, 2018). These functions can also be explored on maps (Connellan, 2012; Ehrensvärd, 1982; Ehrensvärd, 1987; Novin, 2016). For example, decoration is thought to be the main purpose for colours on historical London maps (Darlington \& Howgego, 1964; Hodgkiss, 1981; Krogt, 2008; Whitfield, 2006). Moreover, cultural and commercial information has been recorded on maps (Novin, 2016) from the time when the process of making Royal maps started in the $13^{\text {th }}$ century England (Delano-Smith, 2006). So it could be argued, that creators of maps and graphic design, through visual signs, aim to achieve similar purposes, and fulfil similar functions.

Although the Nuremberg Chronicle, printed by Anton Koberger in 1493 contains text and visual illustrations, which included a view of cities (urban maps), Eskilson (2012) studied typography as a means to analyse the whole designed page rather than an 'urban map'. The illustrations (images) in this book were not considered separately, although they could be studied as examples of graphic design. Thus, the shapes, colours and space on each image and what pieces of information were translated by them were overlooked. Eskilson (2012) suggested these maps are a type of 'visual realism' of history, he ignored the issues of graphic design on maps, even though he did understand that whole images can have symbolic meaning and how these translate 'religious or secular' information about 'the world and its contents' for communication (Barnard, 2013, p.13).

Therefore, there are links and similarities between graphic design and historical urban maps. This graphic design understanding of maps not only offers knowledge for researching symbols, functions, meanings of graphic elements, but also suggests graphic design approach can be used for understanding visual language on historical urban maps.

\section{Using Information Design Principles to Understand Colour on Historical Maps}

'Information design can be thought of as the professionalization of another communication phenomenon: the emergence of a new language. Visual language is defined as the tight coupling of a words, images, and shapes into a unified communication unit' (Horn, 1998 in Jacobson, 1999, p.27).

Graphic elements are used to translate information for functional and visual communication, usually in form of symbols in both graphic design and maps (Andrews, 1996; Bagrow, 1964; Booth, 1986; Dorling \& Fairbairn, 1997; Ehrensvärd, 1987; Fels \& Wood, 1993; Hodgkiss, 1981; Miller, 2003; Opach, 2009; Propen, 2007; Seager, 2004; Thrower, 1972;). For example, a particular shape of roofs represents 'churches' on maps in the $16^{\text {th }}$ century of Germany (Hodgkiss, 1981). This process of producing meaning through shapes matches the approaches within information design, whose main function is defined as visual communication of information (Jacobson, 1999). In the following, we add a reflection on how colour may be use on maps for information design. Colour has been considered part of a visual language that translates information through a visual process into a psychological understanding (Connellan, 2012; Feisner \& Reed, 2014). Connellan (2012) discussed the meanings of white in visual communication, or Feisner and Reed's (2014) analyse cultural symbolic use of colours from the Middle Ages Christian Church. Designed images always purposefully communicate through the composition of graphic elements, such as shape and colours - in this section; the focus will be on the meanings and communicative potential of colour. (Gage, 1999; Itten 1970). Colour can translate information for an audience, as has been studied in various areas of graphic design (Lupton $\&$ Phillips, 2008) and also in the role of colour language for designing commercial posters in the 1890s (Crowley \& Jobling, 1996). Thus, colour plays an important role in visual media, for communication.

Information Design as a sub-discipline of Graphic Design is particularly well suited to the communication of complex information or data sets, in an efficient way, to be immediately accessible for the viewer. Maps contain complex information and data of cities, which is represented by graphic elements. As maps' primary function is to bring increased understanding to their readers, a deeper understanding of the visual language and principles employed by Information Design, could be particularly useful to better understand colour use on historical maps. The Graphic Design and Information Design perspectives of colour use are more than the general understanding that 'beautiful' colour is used to decorate historical London maps.

Colour has generally been understood to be for the purpose of decoration on those urban maps, especially historical hand-coloured London maps (Brown, 1977; Darlington \& Howgego, 1964; Hodgkiss, 1981; Krogt, 2008; Whitfield, 2006). If, as argued here, historical urban maps are considered to be graphic/information design, then their colours could have other functions and richer meanings than just decoration. Understanding visual language is to consider the role of visual representation and social meanings for communication (Connellan, 2012): for example, colours that represent objects, such as the sun as yellow. 
An example of this is the specific application and understanding of colour associated with way finding design: signs in hospital environments are often colour coded to aid visitors in navigation and to communicate clearly, instantly and effectively, such as the top colour is between blue and green for young people (Coad \& Coad, 2008; Jacobson, 1999). Thus, colour language is used to represent information for visual communication. The usage of colour could be suggested to play the same role in mapping areas. An example of this same function is through colours used for direction on maps (Ehrensvärd, 1987; Gage, 1938). So we can conclude, that the information design perspective can be used for understanding colour use and their meanings on maps. However, different cultural understandings influence meaning of colour. For example, different countries used different colours to explain direction on maps in the past, such as Babylonians used colour white for 'South', Israel used green for 'South' and red means 'South' in ancient china (ibid). Therefore, there are cultural differences of colour language in visual communication. This means cultural meanings have to be considered when researching colour.

\section{Applying Graphic Design Methodology: Using Semiotics to Find Rich Meaning}

Building on the idea of maps as a type of Graphic Design, the method of semiotic analysis, used for exploring signs and symbols in graphic design fields, will be applied here to research historical urban maps. The often relatively personal methods of producing maps before the $18^{\text {th }}$ century, as well as the haphazard methods of collecting and archiving them, means that there is often a paucity of supporting information on their exact dates of creations, the names and locations of their printers, and associated crucial aspects of their design, marketing and distribution, for example. These factors, as well as the prevailing unscientific means of surveying and representation, militate against the reliable use of maps from this period as objective historical sources. In this context, we propose here the use of methods of visual semiotic analysis to reveal more latent kinds of information and socially relevant meanings. The aim will be to explore the implied, hidden or latent functions of graphic elements within historical images.

Understanding the meanings of graphic elements supports a better understanding of their functions, such as: explanation, representation or highlighting of information. Semiotics helps to understand the process of internal meanings, suggesting different purposes and functions, see (Howells and Negreiros, 2012; Hielmslev, 1961 cited in Chandler, 2014; Jewitt and Oyama, 2001; Lacey, 1998; Saussure, 1983 cited in Chandler, 2014; Zantides, 2014) for exploring meanings of graphic elements. This can include cultural meanings (Chandler, 2014; Howells and Negreiros, 2012; Leeuwen, 2001) and also the understanding of any language and meaningful communication as a set of codes (Chandler, 2014). The graphic design understanding suggests methods have to focus more on semiotic analysis, which supports understanding and exploring meanings of graphic elements, and this can be applied for researching the functions, meanings, and purpose of graphic elements in maps.

\section{A case study of colours on historical London maps}

This section applies the Graphic Design perspective to discuss colour usage on historical London maps (samples of London maps in the Civitates Orbis Terrarum), utilizing the method of semiotic analysis to explore colour language on these maps.

Researching London maps as a subject has to focus its beginning in the $16^{\text {th }}$ century. Small images of cities with illustrations appeared in the Middle Ages (Whitfield, 2006). The whole view of cities only became published as 'maps' during the $16^{\text {th }}$ century, with the first whole pictures of London as maps published around 1550 (Whitfield, 2006). However, the first London colour map was created in 1572 (Goss, 1992), so researching colour use on London maps has a time limitation of late $16^{\text {th }}$ century.

There are two ways to approach the analysis of hand coloured historical London maps - analysing original map artefacts from archive offices, or analysing digital copies made from these original documents. It is a worthwhile process of reading original archives, especially when researching colours in relation to them. However, this approach poses an issue with regards to coding data and comparing details across maps that may be held by different offices. It is in this case necessary to note all of the information on a map for coding colours when referring to these archival documents. The danger is information will be missed and/or unclear explanations will be noted when recording data from the original sources. Compared with analysing the original document, coding information with that piece of image on the map for visual analysis of data collection is better as it allows spending more time on each document as well as referring to multiple documents simultaneously, especially when researching applied colours. In addition, the location of environments can influence the understanding of colours when reading the original documents from different archives. For example, colour perception is influenced by light. This poses the issue of how to code images.

The only solution to this approach is to take photographs, or scan them when noting information from these maps. However, there are many elements that can influence the colours on copies made by personal collection. For example, the different qualities of light, different cameras or different scanners can all affect the reproduction of colour. Digital copies of maps from archive offices are professionally reproduced and defines colours from original images as closer to a common understanding of 
how colour appears in nature. Therefore, compared with researching colours from original archives, the use of digital copies from archive offices offers more flexibility and less subjectivity with respect to analysis.

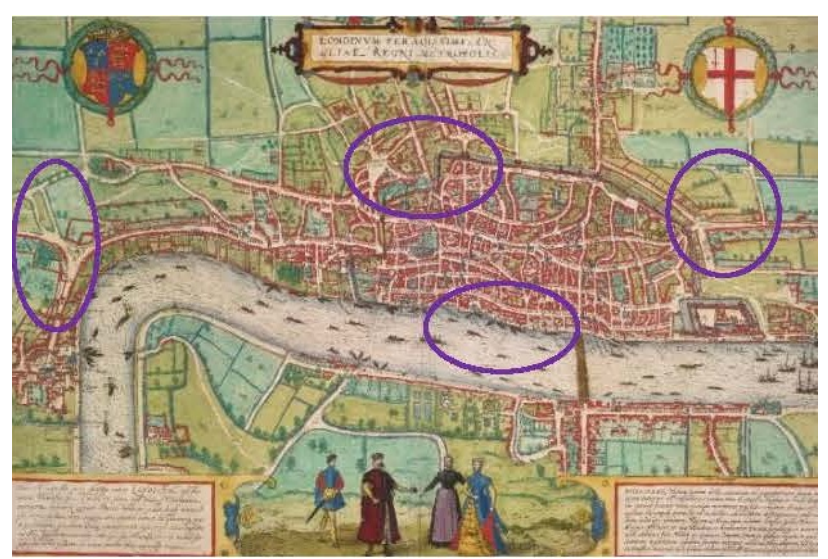

Figure 1. London map, (C) British Library Board, 215.f.1, Copyright 2018.

This research relies on primary resources, that is to say, all of the data is based upon the collection of and analysis of maps. According to the method of semiotic analysis in the Graphic Design field mentioned above, four areas were chosen as samples on this London map (Figure 1: purple). These four areas feature famous buildings and could offer the potential of additional records about their history being available to supplement the analysis. The categories of data collection here are the four basic elements: buildings, roads, open areas and water systems. The information (The definition of colour; the subject was coloured; the information of this subject) was collected from four elements on four areas on each map. This created a large amount of data which was then analysed and compared through the use of software. The data was collected in a common form for systematic coding in NVivo for analysis (Figure 2). The semiotic analysis of colour use relies on the data from these categories. For example, the definition of colour (from the colour theories: Gage, 1938 and Itten, 1970) within one of four basic elements like buildings combined with basic information of the specific building. Through exploring the links between colour and information, we may identify possible function and meaning of colour on these London maps.
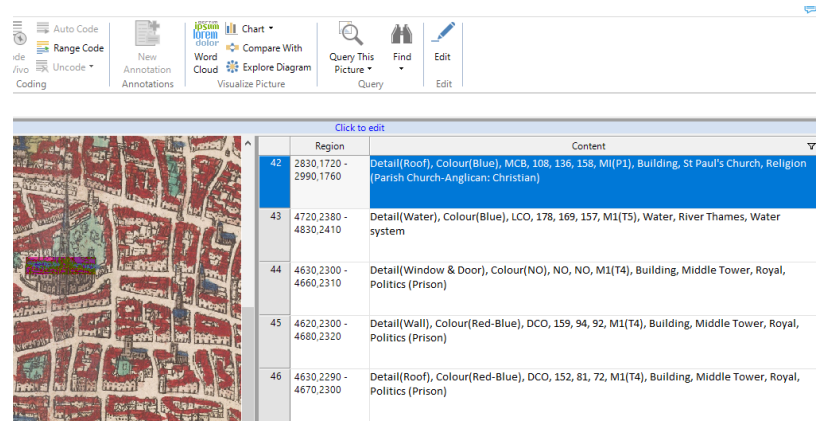

Figure 2. The data of a London map in the NVivo 12.
Decoration has previously been the main understanding of the purpose of colour use on these historical London maps. This suggests an aesthetic understanding of using colours by the map artists. Even the decorative use of colour already achieves a level of purposeful design. However, considering shapes and colours in the example of the London map in the first volume of Civitates Orbis Terrarum (Figure 1), it is clearly evident that there is a consistent colour scheme used. An example of this is different types of buildings are simply identified by shapes on the original black and white map. However, there are two colour schemes designed for making public buildings prominent by differences of colour use. This purposeful, systematic application of colour suggest that Graphic Design and Information Design understanding is involved when map artists chose colours for these maps.

Two colour schemes on the buildings can be understood from looking at colour grammar in historical cartography (Lynam, 1953), red and blue may represent a meaning that corresponds with natural colours of roofs on London maps. However, colours used represented the culture of cities appeared on historical urban maps. For example, blue used for the roof of public buildings on historical London maps (Figure 1). This colour choice can be suggested by St. Paul's Cathedral use of lead and timber, which offer references for natural colouration (Keene, 2008; Porter, 2001; Whitfield, 2006). However, high status buildings in Nuremberg were roofed in copper (and still are today), which transforms into a bright green Verdigris hue in a short period of time (Gnesin, 2015). Thus, different colours were used for the roof of public buildings on these two cities' historical maps. Therefore, colour not only represented the natural views of cities on historical urban maps, but also represents the culture of cites by a certain colour choice for high status buildings representing political or religious power.

If these colours reflect a completely naturalistic view of cities at the time when the maps were made, this would indicate a limitation to an approach to analyse colour through semiotics, from a Graphic Design perspective. Careful viewing though, reveals that the roofs of most buildings are coloured red, and in some instances blue on the London map (Figure 1). However, they are not coloured consistently. This seems to suggest a 'thoughtless' and arbitrary application of colour. In this understanding, these colours would be merely an enhanced representation of naturalism for decorating the image to represent the view of the city. Therefore, when compared with colours that are accurate naturalism (as in a replica of nature as it is), they are closer to naturalism which is influenced by aesthetics (as in a style or conscious choice).

However, the chosen colour language and application may not be that simplistic - the information presented could be more complex, i.e. more consciously (graphically) designed. If the colours are being applied without thought for accuracy, then perhaps they are applied for an 
alternative purpose. There might be a meaning to the colour application. Therefore, application of colours on this map brings up questions for deeper discussion and research.

The way red is used on this is moving towards a more symbolic function, on a design level. To explain this further: the roofs are all covered by a thick red line, there are even details of a building on the map (Figure 1). The use of red is a symbolic representation of common buildings, or a reflection of the natural colour of roofs, which is more than just decorative use of colour. This will be discussed by examples in the following paragraph. Therefore, this approach of using these colours on maps suggests the graphic design understanding.

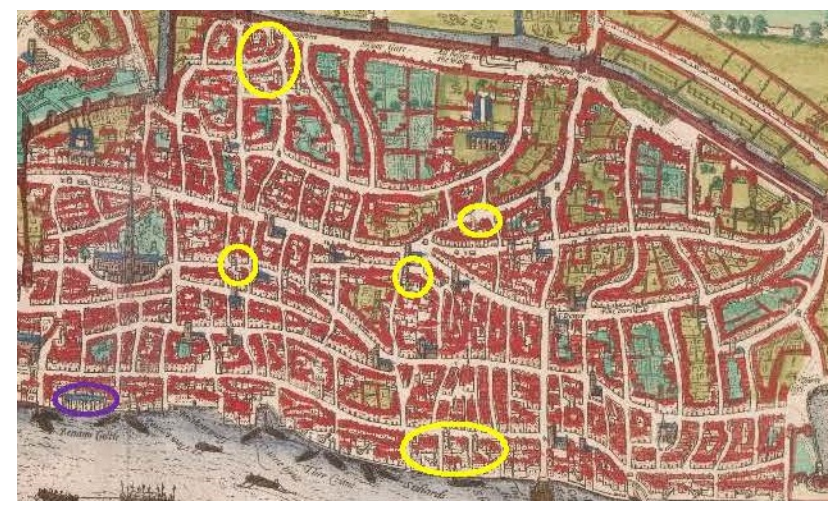

Figure 3. A part of London; The Thames, (C) British Library Board, 215.f.1, Copyright 2018.

As in the discussion above, blue roofs could be naturalistic representations. This does not mean this colour cannot have another function or meaning. Actually, the colour choice by the map artists suggests the function of the colour blue. Map artists often used the differences between two colours to highlight public buildings, even though these buildings do not have conical roofs (Figure 3: purple). This means artists chose which public buildings were coloured differently from their understanding of the culture of the cities they were mapping. Public buildings often represented power: royalty, religion, social status and culture. Blue is used to highlight importance and functions of these public buildings as a record of London at that time. Therefore, importance of public buildings is suggested by the way they were chosen to be coloured. This is more than just following the colour grammar of cartography. The society, status and power of cities represented by public buildings have been incorporated in the creation process of colouring maps. Therefore, even blue is chosen to represent an aesthetic or cultural understanding of natural colour, the design level of colour choice suggests 'invisible' cultural information of London and mapping is recorded by colour language.

Furthermore, churches were important for a city's development in the $16^{\text {th }}$ century, as they were integral to the management of the population and economy of a city (Haigh, 1993). There are a large number of churches, highlighted with colour on $16^{\text {th }}$ century maps, such as blue roofs with brown walls (Figure 3). These colours clearly show that these buildings were seen differently from common buildings, even though churches are already identified by the shape of their roofs. However, many churches with the same shape are left uncoloured (Figure 3: yellow), and these uncoloured public buildings highlight the importance and information that has been assigned to and represented by colour, where they have been applied to buildings. So it can be concluded, that 'invisible' information about these buildings such as associations with royalty, religion and culture are recorded by and encoded within colours. This suggests colours have deeper meanings on historical London maps, which contributes to their function as a means of information to the reader.

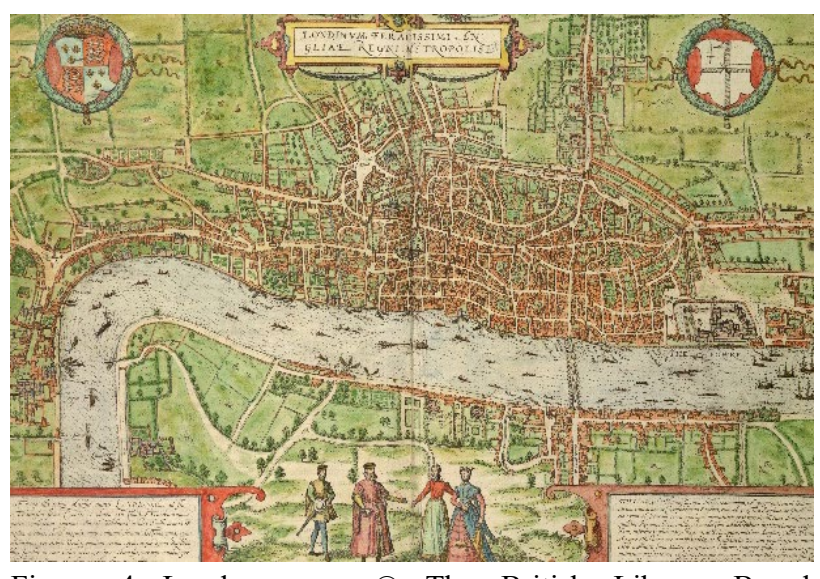

Figure 4 London map, (C) The British Library Board, Maps.C.29.e.1, A.

Moreover, the historic changes and developments of London also are recorded by colour language on these maps. There is another hand-coloured copy from the same original black and white London map in the volume of Civitates Orbis Terrarum (Figure 4). This map was published in the $17^{\text {th }}$ century. An interesting point is the number of churches on this map is the same as the map published in the $16^{\text {th }}$ century (Figure 1). However, there are less churches with roofs coloured blue on this map. This matches with the changes in religious persuasion in London at that period of time (Haigh, 1993). 'The dissolution of the religious houses in the few years after $1535^{\prime}$ caused many religious buildings to be dismantled or to change function (Whitfield, 2006, p.25). This could be the reason that there are less blue roofs on this map (Figure 4). The colours used on this map again suggest that even though the choices in colouring these urban maps might follow a common understanding of how colour appear in nature, the colour choice by the map artists represents some cultural information on a graphic design level. Therefore, colour as a visual language recorded cultural information which is about more than just decoration on historical London maps. This means colour, similar to shape or context on historical urban maps can be used for tracking history of cities. Understanding colour language on historical London maps from the Graphic Design and Information Design perspectives support a better understanding about the history of mapping and cities. Especially, the 'invisible' historical changes can be 
identified by colours rather than the original black and white maps.

\section{Conclusion}

Semiotic analysis has been applied on historical coloured London maps. This suggests a level of purposeful design within colour use on historical urban maps. We can understand maps from the perspective of Graphic Design in terms of visual language and aesthetic style. Visual language can be argued to include the use of colour. There are two meaningful ways to analyse historical urban maps, especially researching colour use on them. The original maps offer details with the original perception of colours as intended. This created opportunities to explore useful information, such as colour application. The digital copies of maps can be visually analysed by software. This approach allows for freely noting all of the information for analysis and comparison on one map or across maps. Through semiotic analysis of colour use, their function as more than decoration on historical London maps has been argued for here. Historical changes of London have been shown to be recorded by colour language on these maps. The procedural knowledge of graphic design suggests colours represent visible meanings, in particular the status/power indicators of London on maps. Therefore, exploring meanings of colour from a graphic design perspective supports a better understanding of historical urban maps and history.

\section{Acknowledgements}

I would like to thank my supervisors and English lecturers who are guiding me to do the $\mathrm{PhD}$ research at the University of Portsmouth. Especially to Dr Simone Gumtau and Anne-Kathrin Reck who gave me the best support in writhing this paper.

\section{References}

Andrews, J. (December 1996). What was a map? The lexicographers reply. Cartographic: The International Journal for Geographic Information and Geovisualization, Volume 33. Issue 4. pp. 1-12. Retrieved

from: https://edisciplinas.usp.br/pluginfile.php/1825017/mod resour ce/content $/ 2 /$ what $\% 20$ was $\% 20 \mathrm{a} \% 20$ map $\% 3 \mathrm{~F}$.pdf

Bagrow, L. (1964). History of cartography. C. A. WATTS \& CO. LTD. London.

Bagrow, L. (2010, 2nd English edition). History of Cartography. Transaction Publishers. New Brunswick \& London.

Barnard M. (04, 07, 2013). Graphic design as communication. Retrieved from: https://ebookcentral.proquest.com/lib/portsmouthebooks/detail.action?docID $=1273176$

Booth, J. (1986). Our Forgotten History: the early map makers. Cambridge house books. Warminster.

Brotton, J. (2014). Great Maps: The World's Masterpieces Explored and Explained. Dorling Kindersley Ltd. Harlow.
Brown L. A. (1977). The story of maps. Dover Publications. New York.

Chandler, D. (2014). Signs, Semiotics for Beginners. Retrieved from: http://visualmemory.co.uk/daniel/Documents/S4B/sem01.html

Chen, J. \& Yu S. (2016). Validation of recursive logic in graphic design. Journal of integrated design and process science. 20 (3). pp.71-85. Retrieved from: http://eds.a.ebscohost.com/eds/pdfviewer/pdfviewer?vid=1\&si $\mathrm{d}=2 \mathrm{db} 2515 \mathrm{f}-0 \mathrm{cb} 2-49 \mathrm{c} 2-8116$ -

94c97e55c270\%40sessionmgr4006

Coad, J. \& Coad, N. (2008). Children and young people's preference of thematic design and colour for their hospital environment. Journal of Child Health Care. Vol 12(1). pp. 33-48. Retrieved from: http://journals.sagepub.com/doi/pdf/10.1177/13674935070856 17

Connellan, K. (2012). The social politics of white in design. Delong M \& Martinson B (Eds.). Color and design (pp. 65-88). Berg. London.

Cosgrove, D. (2005). Imago Mundi Vol. 57. Pan 1: 35-54. Retrieved from: http://eds.a.ebscohost.com/eds/pdfviewer/pdfviewer?sid=c227 8886-fab8-49fa-8696-

$85 \mathrm{ca} 7744 \mathrm{f} 358 \% 40$ sessionmgr4010\&vid $=2 \&$ hid $=4113$

Crowley, D. \& Jobling, P. (1996). Graphic design: reproduction and representation since 1800. Manchester university press. Manchester.

Darlington I. \& Howgego J. (1964). Printed Maps of London: circa 1553 - 1850. George Philip \& Son Limited. London.

Delano-Smith, C. (2006). Milieus of mobility: itineraries, route maps and road maps, cartographies of travel and navigation. The University of Chicago press. Chicago.

Dorling, D. \& Fairbairn, D. (1997). Mapping: ways of representing the world. Pearson Education Limited. Harlow.

Ehrensvärd, U. (1987). Color in Cartography: A Historical Survey. In Woodward, D. Art and Cartography: Six Historical Essays (pp. 123-146).

Eskilson, S. J. (2012, 2nd edition).Graphic design: a history. Laurence King Publishing. London.

Feisner, A. \& Reed, R. (2014, 3rd edition). Colour studies. Fairchild Books. New York.

Feldman, L. (12, 03, 2018). Visions of history, told through art. Time. Vol. 191. Issue 10. pp. 54-55. Retrieved

from: http://eds.a.ebscohost.com/eds/detail/detail?vid=1\&sid=60b93 af0-9c81-4730-9dfd-

d02bc94aa2ad\%40sessionmgr4010\&bdata=JnNpdGU9ZWRz LWxpdmU\%3d\#AN=128256516\&db=a9h

Fels J. \&Wood, D. (1993). The Power of Maps. Routledge. London.

Gage, J. (1938). Colour and meaning: art, science and symbolism. Thames \& Hudson. London.

Gage, J. (1999). Colour and Meaning: Art, Science and Symbolism. Thames \& Hudson Ltd. London. 
Gnesin, G. G. (2015, January). Metals and Alloys of the Bronze Age: from Middle to Modern Times. I. Copper and its Alloys. Powder Metallurgy and Metal Ceramics. Volume 53. Issue 9-10. pp. 610-618. Retrieved from: https://link.springer.com/article/10.1007/s11106-015-9657-z

Goss, J. (1992). The city maps of Europe: $16^{\text {th }}$ century town plans from Braun \& Hogenberg. Rand McNally \& Company. Chicago.

Haigh, C. (1993). English Reformations: Religion, Politics, and Society under the Tudors. Clarendon Press. Oxford.

Hodgkiss, A.G. (1981). Understanding maps: a systematic history of their use and development. Wm Dawson \& Son Ltd. Kent.

Howells, R. and Negreiros, J. (2012, 2nd edition). Visual Culture. Polity Press. Cambridge.

Itten, J. (1970). The Elements of Color. Van Nostrand Reinhold. New York.

Jacobson, R. (1999). Information design. The Massachusetts Institute of Technology Press. Massachusetts.

Jervis, W. W. (1936). The World in Maps: A Study in Map Evolution. George Philip \& Son. London.

Keene, D. (2008). Tall Buildings in Medieval London: Precipitation, Aspiration and Thrills. The London Journal. 33:3. pp. 201-215. Retrieved from: https://www.tandfonline.com/doi/abs/10.1179/174963208X34 7682

Krogt, P. V.D. (2008). Mapping the towns of Europe: The European towns in Braun \& Hogenberg's Town Atlas, 1572-1617. Belgeo. pp. 371-398. Retrieved from: https://journals.openedition.org/belgeo/11877

Lacey, N. (1998). Image and Representation: Key Concepts in Media Studies. PALGRAVE. New York.

Leeuwen, T. V. (2001). Semiotics and Iconography. In Jewitt, C. and Leeuwen, T. V. (Eds.). Handbook of Visual Analysis (pp. 92-118). SAGE Publications. London.

Lupton, E. \& Phillips J. C. (2008). Graphic design: the new basic. Princeton Architectural Press. New York.

Lynam, E. (1953). The mapmaker's art: essays on the history of maps. The Batchworth Press. London.

Miller, N. (2003). Mapping the city: the language and culture of cartography in the renaissance. Continuum. London.

Noble, I. (2016, $3^{\text {rd }}$ edition). Visual research: an introduction to research methods in graphic design. Fairchild Books (an imprint of Bloomsbury Publishing Plc). London.

Novin, G. (2016). A History of Graphic Design. Retrieved from: http://guity-novin.blogspot.co.uk/2010/02/history-ofgraphic-design-maps.html

Opach, T. (12, 10, 2009). Chapter 13: Cartography and Graphic Design. Cartography in Central and Eastern Europe (pp. 199-210). Retrieved from: https://link.springer.com/chapter/10.1007/978-3-642-032943_13

Owen, W. (2005). Mapping: an illustrated guide to graphic navigational systems. Rotovision SA. Brighton.

Porter, R. (2001). London: A Social History. Harvard University Press. Cambridge.

Propen, A. $(02,12,2007)$. Visual communication and the map: how maps as visual objects convey meaning in specific contexts. Technical communication quarterly. Volume 16, 2007. Issue 2. pp. 233-254. Retrieved from: https:/www.tandfonline.com/doi/full/10.1080/105722507093 36561 ?scroll=top\&needAccess $=$ true

Salchow, G. (1997). Graphic design is not a profession. In Heller, S. \& Finamore M. (Eds.). Design culture: an anthology of writing from the AIGA journal of graphic design (pp. 83-84). Allworth Press. New York.

Seager, J. (2004). Maps. George Mason University. Retrieved from: http://chnm.gmu.edu/worldhistorysources/unpacking/mapsgui de.pdf

Skelton, R. A. (1966, 2nd edition). History of Cartography. Precedent Publishing. Chicago.

Thrower, N. J. W. (1972). An Examination of Cartography in Relation to Culture and Civilization. Prentice-Hall. Englewood Cliffs.

Triggs, T. (2011). Graphic design history: past, present and future. Design Issues. Volume 27. pp. 3-6. MIT Press. Retrieved from: http://eds.a.ebscohost.com/eds/pdfviewer/pdfviewer?vid=1\&si $\mathrm{d}=9468 \mathrm{f} 728-8407-43 \mathrm{a} 8$-a455ac8d948b20f5\%40sessionmgr4010

Walker, S. (31, 07, 2017). Research in graphic design. The design journal. Volume 20, 2017. Issue 5. pp. 549-559. Retrieved

from: https://www.tandfonline.com/doi/full/10.1080/14606925.2017 .1347416 ? scroll=top\&needAccess $=$ true

Whitfield, P. (2006). London: A life in maps. The British Library. London.

Zantides, E. (2014). Semiotics and Visual Communication: Concepts and Practices. Cambridge Scholars Publishing. Newcastke upon Tyne. Retrieved from:

http://site.ebrary.com/lib/portsmouth/reader.action?docID=108 60012\&ppg=19 